\title{
EMERGÊNCIA DE PLÂNTULAS DE TUCUMÃ (Astrocaryum aculeatum) EM FUNÇÃO DO PRÉ-TRATAMENTO DAS SEMENTES E DA CONDIÇÃO DE SEMEADURA ${ }^{1}$
}

\author{
SIDNEY ALBERTO DO NASCIMENTO FERREIRA², ANDREIA FERNANDES DE CASTRO 3 , \\ DANIEL FELIPE DE OLIVEIRA GENTIL ${ }^{4}$
}

RESUMO - O objetivo desta pesquisa foi avaliar os efeitos de diferentes condições de embebição das sementes, associadas a diferentes substratos e ambientes de semeadura, sobre a emergência de plântulas de tucumã (Astrocaryum aculeatum). O delineamento experimental foi o inteiramente ao acaso, em esquema fatorial 2 (condições de embebição da semente: à sombra e a pleno sol) x 3 (substratos de semeadura: areia, serragem de madeira e areia + serragem) x 3 (sombreamentos do viveiro: $30 \%, 50 \%$ e $70 \%$ ), com três repetições de 25 sementes. A semeadura foi feita em caixas de plástico, contendo os diferentes substratos, cobertas com filme de polietileno transparente, formando um estufim. A emergência e o índice de velocidade de emergência (IVE) apresentaram efeito de interação entre os fatores "condição de embebição" e "substrato de semeadura". A semeadura em serragem de sementes embebidas à sombra $\left(26-27^{\circ} \mathrm{C}\right)$ proporcionou emergência de $73 \%$ e IVE de 0,710 , sendo esses valores significativamente superiores aos obtidos em sementes embebidas a pleno sol $\left(26-42{ }^{\circ} \mathrm{C}\right)$, que alcançaram $58 \%$ e 0,578 , respectivamente. Os sombreamentos de $30 \%$ e $50 \%$ proporcionaram o mesmo percentual de emergência (68\%), que foi superior aos $44 \%$ de emergência alcançada sob $70 \%$ de sombreamento. Os ambientes de semeadura com maiores amplitudes térmicas $\left(13-14{ }^{\circ} \mathrm{C}\right)$ e que atingiram maiores temperaturas médias $\left(38-39^{\circ} \mathrm{C}\right)$, favoreceram o processo germinativo de sementes de tucumã. Desse modo, o melhor desempenho de emergência de plântulas foi alcançado com pré-embebição das sementes à sombra e semeadura em serragem de madeira, sob estufim mantido em viveiro com sombreamento de $30 \%$ e $50 \%$.

Termos para indexação: Arecaceae, embebição, substrato, temperatura, estufim.

\section{EMERGENCE OF TUCUMÃ (Astrocaryum aculeatum) SEEDLINGS ACCORDING TO SEED PRE-TREATMENT AND SOWING CONDITION}

\begin{abstract}
This research evaluates the effects of different conditions of seed soaking, associated with different substrates and shade levels on the emergence of tucumã (Astrocaryum aculeatum) seedlings. The experimental design was entirely randomized with three replicates and 25 seeds. The treatments form a factorial of 2 conditions of seed soaking (shade and full sun) x 3 sowing substrates (sand, sawdust and sand + sawdust) $x 3$ levels of shade $(30 \%, 50 \%$ and $70 \%)$, The seeds were sown in plastic boxes containing the substrate and covered with transparent polyethylene film, forming mini greenhouses. The emergence and emergence velocity index (EVI) showed interaction between the factors "soaking condition" and "sowing substrate". Seeds soaked in the shade $\left(26-27^{\circ} \mathrm{C}\right)$ and sown in sawdust showed $73 \%$ emergence and an EVI of 0.710 , values significantly higher than those $(58 \%$ and 0.578$)$ obtained for seeds soaked in full sun (26$42{ }^{\circ} \mathrm{C}$ ). The $30 \%$ and $50 \%$ shade levels gave the same percentage of emergence $(68 \%)$ which was higher than the $44 \%$ emergency obtained with $70 \%$ shade. Environments with a higher temperature range (13-14 $\left.{ }^{\circ} \mathrm{C}\right)$ and higher average temperatures $\left(38-39^{\circ} \mathrm{C}\right)$ promoted the process of seed germination. Thus, the best emergence of tucumã seedlings was achieved with seeds pre-soaked in the shade, sown in sawdust, under transparent polyethylene film and kept at $30 \%$ or $50 \%$ shade.
\end{abstract}

Index terms: Arecaceae, seed soaking, substrate, temperature, mini greenhouse.

\footnotetext{
'(Trabalho 261-09). Recebido em 15-11-2009. Aceito para publicação em: 27-04-2010.

${ }^{2}$ Pesquisador INPA - CPCA, Manaus-AM, sanf@inpa.gov.br

${ }^{3}$ Eng. Flo., Bolsista INPA - PCI, Manaus-AM, andreiacastro_5@hotmail.com

${ }^{4}$ Professor, UFAM - FCA, Manaus-AM, dfgentil@ufam.edu.br
} 


\section{INTRODUÇÃO}

Algumas palmeiras que compõem a flora amazônica apresentam importância nutricional, ornamental e econômica, sendo utilizadas para suprir necessidades diversas dos habitantes locais, como alimentação, cobertura de casas, confecção de utensílios e artesanatos, dentre outros fins. Normalmente, são propagadas por sementes que, muitas vezes, apresentam germinação lenta, irregular e em baixa porcentagem.

Em palmeiras, a dormência tem sido atribuída, em parte, à resistência mecânica ou à impermeabilidade à água das partes integrantes da cobertura protetora das sementes (OROZCO-SEGOVIA et al., 2003). A ruptura do endocarpo e a embebição das sementes em água, com troca diária por 1 a 7 dias, podem acelerar o processo germinativo (MEEROW, 2001). Desse modo, é necessário o conhecimento de técnicas de superação da dormência, que acelerem e uniformizem a germinação, bem como elevem o percentual de sementes germinadas dessas espécies.

A água é o fator de maior influência sobre o processo germinativo. Com a absorção de água por embebição, ocorre a reidratação dos tecidos e, consequentemente, a intensificação da respiração e de todas as outras atividades metabólicas que resultam no fornecimento de energia e nutrientes necessários à retomada do crescimento do eixo embrionário (NASSIF et al., 1998).

Outro fator que afeta a germinação é o substrato utilizado, pois as características de aeração, estrutura, capacidade de retenção de água, presença de patógenos, dentre outras, podem variar de um material para outro e, com isso, favorecer ou prejudicar a germinação de sementes (POPININGIS, 1985). Em testes de laboratório, a escolha do substrato é feita, geralmente, em função do tamanho e do formato da semente a ser analisada (BRASIL, 1992). Em palmeiras, a vermiculita é o substrato mais utilizado para a germinação, pois apresenta boa drenagem, boa porosidade e alta capacidade de retenção de umidade. Nesse substrato, as sementes germinadas apresentam bom desenvolvimento do sistema radicular e ficam menos sujeitas a enfermidades (YOCUM, 1964). Conforme Ferreira (2005), a serragem de madeira e a areia, ou mistura de ambos, utilizadas como substrato, proporcionam bons resultados na germinação de sementes de pupunha (Bactris gasipaes).

A temperatura também influencia na porcentagem e na velocidade de germinação, afetando a absorção de água pela semente e as reações bioquímicas que regulam o metabolismo envolvido neste processo (BEWLEY; BLACK, 1994). A maioria das sementes de palmeiras apresenta temperatura ótima de germinação entre $30{ }^{\circ} \mathrm{C}$ e $35^{\circ} \mathrm{C}$ (BROSCHAT, 1994). Adicionalmente, o pré-tratamento com aquecimento na faixa de $38{ }^{\circ} \mathrm{C}$ a $40{ }^{\circ} \mathrm{C}$, durante vários dias, tem sido prática comum para estimular a germinação de sementes de algumas espécies (ADDAE-KAGYAH et al., 1988).

O tucumã (Astrocaryum aculeatum) é uma palmeira de estipe solitário, com até $20 \mathrm{~m}$ de altura e $30 \mathrm{~cm}$ de diâmetro, e internós densamente espinhosos (HENDERSON; SCARIOT, 1993). A polpa do fruto pode ser consumida in natura ou usada na elaboração de sorvete, "vinho" e patê; o endocarpo e as folhas são usados na confecção de diversos tipos de artesanato (MIRANDA et al., 2001). No Brasil, ocorre nos Estados do Acre, Amazonas, Pará e Rondônia, sendo comum nas áreas de formações florestais menos densas e capoeiras, em terrenos bem drenados e próximos a núcleos populacionais (LORENZI et al., 1996). É uma espécie excepcionalmente tolerante a solos ácidos e pobres em nutrientes (COSTA; LEEUWEN, 2002).

Normalmente, a germinação de sementes de tucumã pode durar de dois (SÁ, 1984) a três anos (KOEBERNIK, 1971). Entretanto, Ferreira e Gentil (2006) verificaram que a extração do endocarpo favoreceu a redução do período de germinação, com início aos 41 dias e finalização aos 164 dias após a semeadura, apresentando percentual de germinação de $66 \%$ (estádio de "intumescimento do pecíolo cotiledonar"). Adicionalmente, antecedendo a semeadura, a embebição das sementes em água, por 9 dias, antecipou o tempo médio de emergência do pecíolo cotiledonar (99 dias) e o de completa expansão da primeira folha bífida (253 dias) (GENTIL; FERREIRA, 2005). Apesar dos benefícios obtidos com a aplicação desses tratamentos pré-germinativos, o período de germinação ainda é considerado longo. Contudo, o aperfeiçoamento e/ou, a associação de procedimentos que deram bons resultados poderá contribuir para a redução do tempo de germinação. Assim, o objetivo desta pesquisa foi avaliar os efeitos de diferentes condições de embebição das sementes, associadas a diferentes substratos e ambientes de semeadura, sobre a emergência de plântulas de tucumã.

\section{MATERIAL E MÉTODOS}

O ensaio foi desenvolvido no Laboratório de Sementes e nos Viveiros da Coordenação de Pesquisas em Ciências Agronômicas (CPCA) do Instituto Nacional de Pesquisas da Amazônia, em Manaus, Amazonas. As sementes foram obtidas de pirenos (endocarpo + semente), resultantes de uma mistura de 
progênies, adquiridos logo após a extração da polpa. Inicialmente, os pirenos foram mantidos em água por três dias, trocada diariamente, a fim de facilitar a retirada dos restos de polpa aderidos ao endocarpo. Após a lavagem, os pirenos foram colocados para secar, sob condições de ambiente natural, até o desprendimento interno das sementes (46 dias), quando o endocarpo foi quebrado e a semente extraída, conforme Ferreira e Gentil (2006). Depois, as sementes foram colocadas para embeber em água, a pleno sol e à sombra (sob temperatura ambiente), por nove dias, conforme recomendado por Ferreira e Gentil (2006). Nas duas condições, diariamente, foi monitorada a temperatura da água de embebição, nos seguintes horários: 06 h, 08 h, 10 h, 12 h, 14 h, 16 $\mathrm{h}$ e $18 \mathrm{~h}$. Pela manhã, após o registro da temperatura das $06 \mathrm{~h}$, foi feita a troca da água.

A semeadura foi feita em caixas de plástico (40 cm de largura x $60 \mathrm{~cm}$ de comprimento x $20 \mathrm{~cm}$ de altura) contendo três diferentes substratos: areia, serragem de madeira e mistura de areia e serragem $(1: 1 ; \mathrm{v}: \mathrm{v})$. Cada caixa foi preenchida com um dos substratos até a altura de $10 \mathrm{~cm}$, permanecendo os outros $10 \mathrm{~cm}$ sem substrato. As sementes foram posicionadas a uma profundidade de $1 \mathrm{~cm}$ (nível do substrato em relação ao nível superior da semente), com o poro germinativo voltado para o lado, formando um ângulo de $90^{\circ}$ em relação a uma linha perpendicular imaginária ao nível do substrato, atendendo à recomendação de Elias et al. (2006). Após a semeadura, as caixas foram cobertas com filme de polietileno transparente (antirraios ultravioleta), preso com elástico, formando um estufim, e mantidas em viveiros cobertos com telas de sombreamento de diferentes níveis: $30 \%, 50 \%$ e $70 \%$ de sombra. Periodicamente, foram avaliadas as temperaturas nos ambientes internos de cada estufim, nos seguintes horários: $06 \mathrm{~h}, 08 \mathrm{~h}, 10 \mathrm{~h}, 12 \mathrm{~h}, 14 \mathrm{~h}, 16 \mathrm{~h}$ e $18 \mathrm{~h}$; os termômetros foram posicionados em pé, sobre o filme de polietileno, com o bulbo voltado para dentro do estufim. Sempre que necessário, foi feita a irrigação dos substratos com água, até atingir a capacidade de campo de cada um. Após vinte dias da instalação do ensaio, e a cada dez dias, foi avaliada a emergência, através da contagem do número de plântulas que surgiram acima do nível do substrato. A partir da contagem da emergência, foi calculado o percentual, o índice de velocidade (MAGUIRE, 1962) e o tempo médio de emergência (EDWARDS, 1934). No encerramento do experimento, aplicando o teste de corte nas sementes não germinadas (BRASIL, 1992), foi computado o número de sementes dormentes (com embriões firmes, sadios e de coloração branco-leitosa) e de sementes mortas (com embriões deteriorados), sendo os resultados expressos em porcentagem.

O delineamento experimental foi o inteiramente ao acaso, em esquema fatorial 2 (condições de embebição: à sombra e a pleno sol) x 3 (substratos de semeadura: areia, serragem e areia + serragem) x 3 (sombreamento: $30 \%, 50 \%$ e $70 \%$ ), com 3 repetições de 25 sementes. Para a análise estatística, os dados em porcentagem foram transformados em arcosseno da raiz quadrada de $\mathrm{x} / 100$; nos resultados, foram apresentados os dados originais. As médias foram comparadas pelo teste de Tukey, a 5\% de probabilidade.

\section{RESULTADOS E DISCUSSÃO}

Durante a embebição, foi verificado que a temperatura da água (Figura 1), à sombra, manteve-se praticamente constante, oscilando entre $26{ }^{\circ} \mathrm{C}$ e $27^{\circ} \mathrm{C}$. A pleno sol, a temperatura aumentou gradativamente até às $16 \mathrm{~h}$, quando atingiu a temperatura média máxima de $42{ }^{\circ} \mathrm{C}$, decrescendo a partir desse horário.

Nos estufins, sob os diferentes níveis de sombreamento, a temperatura média mínima foi $25^{\circ} \mathrm{C}$ (às $6 \mathrm{~h}$ ) e a temperatura média máxima não ultrapassou os $39^{\circ} \mathrm{C}$ (às $14 \mathrm{~h}$ ), com menor amplitude no ambiente com $70 \%$ de sombreamento (Figura 2). No ambiente com $30 \%$ de sombreamento, a temperatura média máxima foi $38^{\circ} \mathrm{C}$ nos estufins com os substratos serragem e areia + serragem; em areia, foi verificada a menor amplitude $\left(11^{\circ} \mathrm{C}\right)$, com temperatura média máxima de $36^{\circ} \mathrm{C}$. No ambiente com $50 \%$ de sombreamento, as temperaturas nos estufins com os substratos areia e areia + serragem foram praticamente iguais em todos os períodos de avaliação, com temperatura média máxima de $38^{\circ} \mathrm{C}$; em serragem, foram constatados os maiores valores de temperatura em todos os períodos de avaliação, com amplitude de $14{ }^{\circ} \mathrm{C}$. No ambiente com $70 \%$ de sombreamento, a temperatura média máxima foi 35 ${ }^{\circ} \mathrm{C}$ nos estufins de todos os substratos.

A análise estatística evidenciou efeito de interação entre os fatores condição de embebição e substrato de semeadura para as variáveis emergência e índice de velocidade de emergência (IVE) (Tabela 1). As sementes embebidas à sombra e semeadas em serragem apresentaram valores de emergência e índice de velocidade de emergência superiores aos das sementes embebidas a pleno sol e semeadas nesse mesmo substrato. É possível que a temperatura média de $42{ }^{\circ} \mathrm{C}$ (com desvio-padrão de até $+/-3^{\circ} \mathrm{C}$ ), alcançada na água de embebição a pleno sol (Figura 1), tenha comprometido, em parte, a viabilidade das 
sementes. Em dendê (Elaeis guineensis), a temperatura ótima de tratamento pré-germinativo de sementes está entre $38-40^{\circ} \mathrm{C}$ (ADDAE-KAGYAH et al., 1988). Nos substratos areia e areia + serragem, os valores destas mesmas variáveis (emergência e IVE) não diferiram quanto à condição de embebição e, dentro do "nível sombra", foram inferiores aos obtidos no substrato serragem.

As condições de embebição não provocaram diferenças significativas no tempo médio de emergência (TME), em "sementes dormentes" e em "sementes mortas" (Tabela 2), indicando que a constância (à sombra) e a flutuação (a pleno sol) da temperatura da água proporcionaram resultados semelhantes para essas variáveis, diferente do que ocorreu com a emergência e o IVE. Nazário (2006), estudando a embebição de sementes de tucumã sob temperaturas constantes $\left(25^{\circ} \mathrm{C}, 30^{\circ} \mathrm{C}, 35^{\circ} \mathrm{C}\right.$ e 40 $\left.{ }^{\circ} \mathrm{C}\right)$, associadas com diferentes períodos $(2 ; 4$ e 6 dias), observou que o TME apresentou efeito de interação entre estes fatores: no período de 4 dias, o TME decresceu linearmente à medida que a temperatura se elevou.

Em relação aos substratos de semeadura, não foi verificada diferença significativa na variável "sementes mortas". No entanto, para o tempo médio de emergência e "sementes dormentes", o substrato serragem proporcionou melhor desempenho (Tabela 2).

Sementes submetidas aos ambientes com maior intensidade luminosa (sombreamento de $30 \%$ e de $50 \%$ ), consequentemente maiores níveis e amplitudes de temperatura, apresentaram me- lhores resultados de emergência, IVE e "sementes dormentes". As variáveis tempo médio de emergência e "sementes mortas" não foram influenciadas pelos níveis de sombreamento, ou regimes de temperaturas.

Segundo Jorge (1985), o solo tem a capacidade de absorver a energia radiante, procedente do Sol, sendo que a quantidade absorvida depende, dentre outros fatores, da cor do solo. A variação na absorção de calor, com a incidência de uma mesma intensidade de radiação, é resultante de diferentes propriedades térmicas do solo, como o albedo, que está relacionado à cor do solo; assim, solos escuros absorvem mais radiação que os solos de cores claras. No presente estudo, foi verificado que, nos ambientes com maior intensidade luminosa, bem como maior amplitude de temperatura e maior temperatura média máxima (30\% e $50 \%$ de sombreamento), as temperaturas nos estufins com o substrato serragem foram geralmente superiores às dos demais substratos (Figura 2). Desse modo, pode ser sugerido que a serragem, por apresentar cor mais escura que as dos demais substratos, absorveu mais calor e, por conseguinte, contribuiu para a elevação da temperatura no interior dos estufins.

Os ambientes com maiores amplitudes térmicas $\left(13-14^{\circ} \mathrm{C}\right)$, e que atingiram maiores temperaturas médias $\left(38-39^{\circ} \mathrm{C}\right)$, favoreceram o processo germinativo de sementes de tucumã (Tabela 2). Segundo Orozco-Segovia et al. (2003), as temperaturas elevadas constantes são, geralmente, inadequadas à germinação de sementes de palmeiras. Por outro lado, a alternância diária de temperatura pode acelerar o processo, como foi verificado em sementes de Sabal causiarum (CARPENTER, 1989).

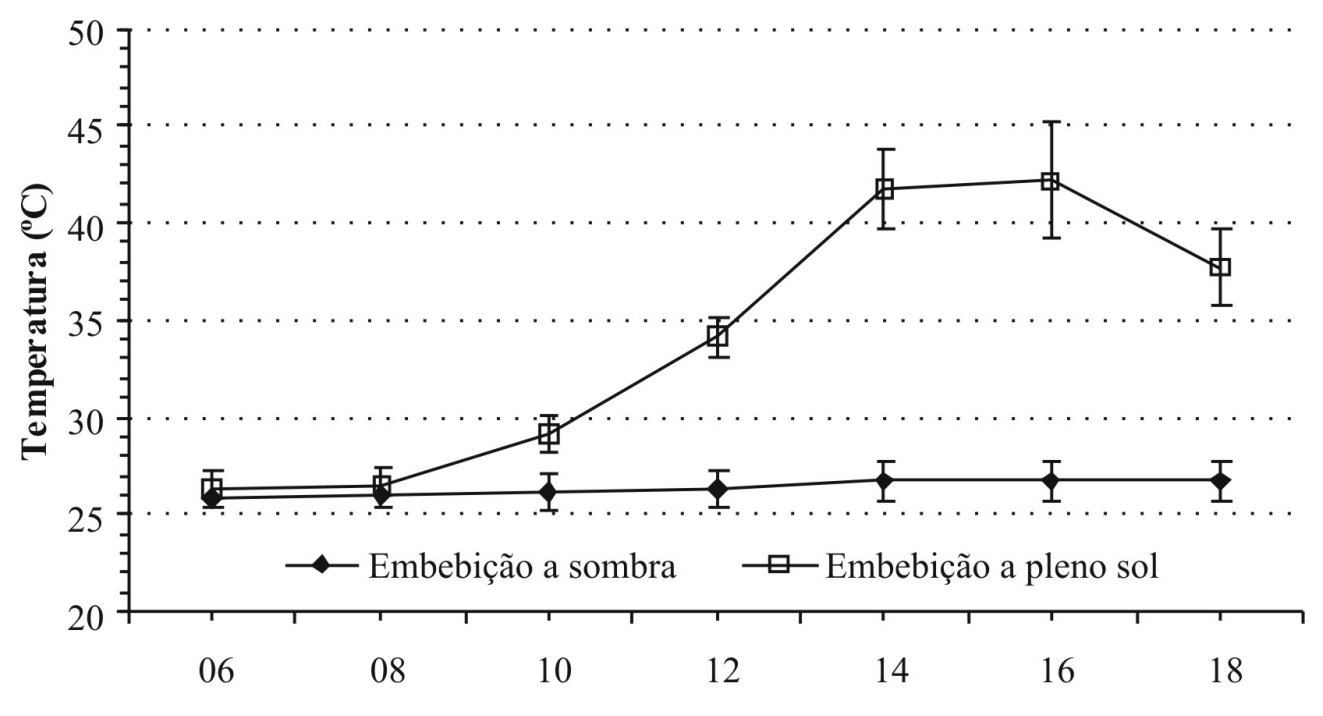

Horas

FIGURA 1 - Temperatura média (+/- desvio-padrão) da água durante a embebição das sementes de Astrocaryum aculeatum, sob sombra e a pleno sol, em Manaus - AM. 

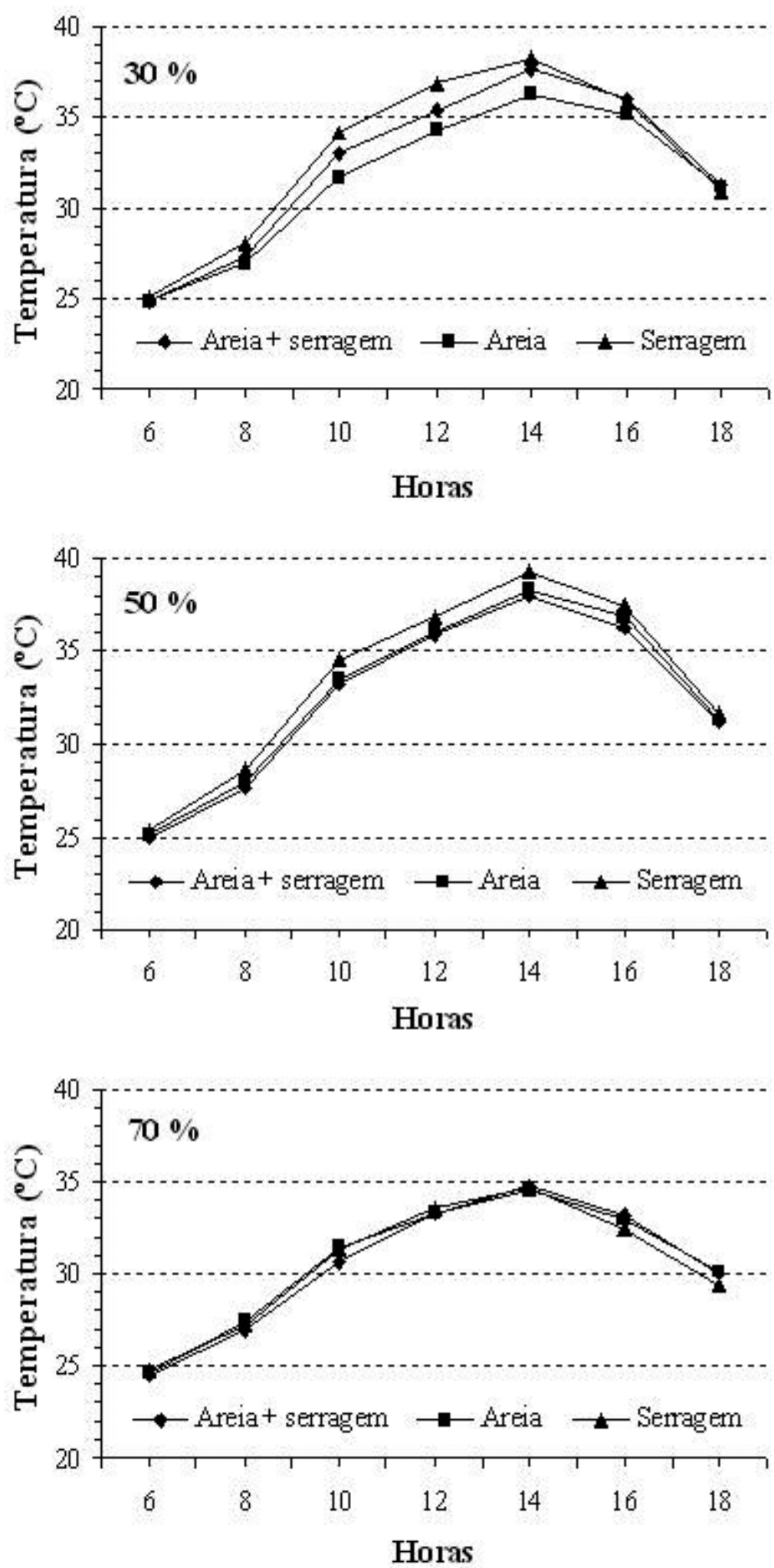

FIGURA 2 - Variação da temperatura nos estufins com diferentes substratos de semeadura (areia + serragem, areia e serragem) e sob diferentes níveis de sombreamento $(30 \%, 50 \%$ e $70 \%)$, em Manaus - AM. 
TABELA 1 - Médias de emergência e índice de velocidade de emergência (IVE) de plântulas de Astrocaryum aculeatum, referentes à interação entre os fatores condição de embebição e substrato de semeadura, em Manaus - AM.

\begin{tabular}{lccc}
\hline \multirow{2}{*}{$\begin{array}{c}\text { Condição de } \\
\text { embebição }\end{array}$} & \multicolumn{3}{c}{ Substrato de semeadura } \\
\cline { 2 - 4 } & Serragem & Areia & Areia + serragem \\
Sombra & \multicolumn{3}{c}{$\begin{array}{c}\text { Emergência (\%) } \\
\text { Sol }\end{array}$} \\
\hline & $53 \mathrm{aA}$ & $56 \mathrm{aB}$ & $54 \mathrm{aB}$ \\
Sombra & $57 \mathrm{aA}$ & $62 \mathrm{aA}$ \\
Sol & $0,710 \mathrm{aA}$ & $0,479 \mathrm{aB}$ & $0,458 \mathrm{aB}$ \\
\hline
\end{tabular}

Médias seguidas de mesma letra minúscula, nas colunas, e maiúscula, nas linhas, não diferem significativamente entre si, pelo teste Tukey, a $5 \%$ de probabilidade.

TABELA 2 - Médias de emergência, tempo médio de emergência (TME), índice de velocidade de emergência (IVE), "sementes dormentes", e "sementes mortas", referentes a sementes de Astrocaryum aculeatum submetidas a diferentes condições de embebição, substratos e sombreamentos, em Manaus - AM.

\begin{tabular}{|c|c|c|c|c|c|}
\hline Fatores & $\begin{array}{c}\text { Emergência } \\
(\%)\end{array}$ & $\begin{array}{l}\text { TME } \\
\text { (dias) }\end{array}$ & IVE & $\begin{array}{c}\text { Sementes dormentes } \\
(\%)\end{array}$ & $\begin{array}{c}\text { Sementes } \\
\text { mortas (\%) }\end{array}$ \\
\hline \multicolumn{6}{|c|}{ Condição de embebição } \\
\hline Sombra & - & $123 \mathrm{a}$ & - & $18 \mathrm{a}$ & $21 \mathrm{a}$ \\
\hline Sol & - & $118 \mathrm{a}$ & - & $16 \mathrm{a}$ & $25 \mathrm{a}$ \\
\hline \multicolumn{6}{|c|}{ Substrato de semeadura } \\
\hline Areia & - & $125 \mathrm{a}$ & - & $24 \mathrm{a}$ & $19 \mathrm{a}$ \\
\hline Serragem & - & $112 \mathrm{~b}$ & - & $11 \mathrm{~b}$ & $24 \mathrm{a}$ \\
\hline Areia + serragem & - & $124 \mathrm{a}$ & - & $16 \mathrm{~b}$ & $26 \mathrm{a}$ \\
\hline \multicolumn{6}{|l|}{ Sombreamento } \\
\hline $30 \%$ & $68 \mathrm{a}$ & $123 \mathrm{a}$ & $0,602 \mathrm{a}$ & $11 \mathrm{~b}$ & $21 \mathrm{a}$ \\
\hline $50 \%$ & $68 \mathrm{a}$ & $116 \mathrm{a}$ & 0,639 a & $8 \mathrm{~b}$ & $24 \mathrm{a}$ \\
\hline $70 \%$ & $44 \mathrm{~b}$ & $121 \mathrm{a}$ & $0,409 \mathrm{~b}$ & $33 \mathrm{a}$ & $23 \mathrm{a}$ \\
\hline CV (\%) & 15,6 & 8,2 & 23,6 & 32,3 & 29,6 \\
\hline
\end{tabular}

Médias seguidas de mesma letra, nas colunas, não diferem significativamente entre si, pelo teste Tukey, a 5\% de probabilidade.

\section{CONCLUSÃO}

O melhor desempenho de emergência de plântulas de tucumã (Astrocaryum aculeatum) é alcançado com pré-embebição das sementes à sombra e semeadura em serragem de madeira, sob estufim mantido em viveiro com sombreamento de $30 \%$ e $50 \%$.

\section{AGRADECIMENTO}

À Fundação de Amparo a Pesquisa do Estado do Amazonas - FAPEAM pelo apoio financeiro a este trabalho.

\section{REFERÊNCIAS}

ADDAE-KAGYAH，K.A.; OSAFO, D.M.; OLYMPIO, N.S.; ATUBRA, O.K. Effect of seed storage, heat pretreatment and its duration on germination and growth of nursery stock of the idolatrica palm, Elaeis guineensis var idolatrica (Chevalier). Tropical Agriculture, St. Augustine, v.65, n.1, p.77-83, 1988.

BEWLEY, J.; BLACK, M. Seeds: physiology of development and germination. 2. ed. New York: Plenum Press, 1994. 445p. 
BRASIL. Ministério da Agricultura e Reforma Agrária. Regras para análise de sementes. Brasília: SNAD/DNDV/CLAV, 1992. 365p.

BROSCHAT, T.K. Palm seed propagation. Acta Horticulturae, Wageningen, n.360, p.141-147, 1994.

CARPENTER, W.J. Influence of temperature on germination of Sabal causiarum seed. Principes, Lawrence, v.33, n.4, p.191-194, 1989.

COSTA, J.R.; LEEUWEN, J. O uso do tucumã (Astrocaryum aculeatum Meyer) por produtores rurais em áreas alteradas e degradadas no Estado do Amazonas. In: SIMPÓSIO NACIONAL SOBRE RECUPERAÇÃO DE ÁREAS DEGRADADAS (SINRAD): ÁGUA E BIODIVERSIDADE, 5., 2002, Belo Horizonte. Anais... Belo Horizonte: SOBRADE, 2002. p.311-312.

EDWARDS, T.I. Relations of germinating soy beans to temperature and length of incubations time. Plant Physiology, Washington, v.9, n.1, p.1-30, 1934.

ELIAS, M.E.A.; FERREIRA, S.A.N.; GENTIL, D.F.O. Emergência de plântulas de tucumã (Astrocaryum aculeatum) em função da posição de semeadura. Acta Amazonica, Manaus, v.36, n.3, p.385-388, 2006.

FERREIRA, S.A.N. Pupunha, Bactris gasipaes Kunt. In: FERRAZ, I.D.K.; CAMARGO, J.L.C. Manual de sementes da Amazônia. Manaus: INPA, 2005. p.1-12.

FERREIRA, S.A.N.; GENTIL, D.F.O. Extração, embebição e germinação de sementes de tucumã (Astrocaryum aculeatum). Acta Amazonica, Manaus, v.36, n.2, p.141-146, 2006.

GENTIL, D.F.O.; FERREIRA, S.A.N. Morfologia da plântula em desenvolvimento de Astrocaryum aculeatum Meyer (Arecaceae). Acta Amazonica, Manaus, v.35, n.2, p.337-342, 2005.

HENDERSON, A.; SCARIOT, A. A flora da Reserva Ducke, I: Palmae (Arecaceae). Acta Amazonica, Manaus, v.23, n.4, p.349-369, 1993.

JORGE, J.A. Física e manejo dos solos tropicais. Campinas: Instituto Campineiro de Ensino Agrícola, 1985. 328p.
KOEBERNIK, J. Germination of palm seed. Principes, Lawrence, v.15, n.4, p.134-137, 1971.

LORENZI, H.; SOUZA, H.M.; COSTA, J.T.M.; CERQUEIRA, L.S.C.; BEHR, N. Palmeiras do Brasil: nativas e exóticas. Nova Odessa: Editora Plantarum, 1996. 320p.

MAGUIRE, J.D. Speed of germination: aid in selection and evaluation for seedling emergence and vigour. Crop Science, Madison, v.2, n.2, p.176-177, 1962.

MEEROW, A.W. Palm seed germination. 2001. (IFAS Cooperative, 274). Disponível em: <http:// ftld.ufl.edu/PALSeed.htm>. Acesso em: 23 fev. 2006.

MIRANDA, I.P.A.; RABELO, A.; BUENO, C.R.; BARBOSA, E. M.; RIBEIRO, M.N.S. Frutos de palmeiras da Amazônia. Manaus: MCT/INPA, 2001. 120p.

NASSIF, S.M.L.; VIEIRA, I.G.; FERNANDES, G.D. Fatores externos (ambientais) que influenciam na germinação de sementes. Piracicaba: IPEF/LCF/ ESALQ/USP, Informativo Sementes IPEF, abr., 1998. 1998. Disponível em: <http://ipef.br/sementes/>. Acesso em: 09 fev. 2006.

NAZÁRIO, P. Tratamentos pré-germinativos visando a minimizar a dormência em sementes de tucumã (Astrocaryum aculeatum G. Mey). 2006. 94 f. Dissertação (Mestrado em Ciências de Florestas Tropicais) - Instituto Nacional de Pesquisas da Amazônia/Universidade Federal do Amazonas, Manaus, 2006.

OROZCO-SEGOVIA, A.; BATIS, A.I.; ROJASARÉCHIGA, M.; MENDOZA, A. Seed biology of palms: a review. Palms, Miami, v.47, n.2, p.79-94, 2003.

POPININGIS, F. Fisiologia da semente. Brasília: AGIPLAN, 1985. 289p.

SÁ, S.T.V. Superação da dormência de sementes de tucumã (Astrocaryum tucuma Mart.). 1984. 53f. Monografia (Graduação em Agronomia) - Universidade Federal do Amazonas, Manaus, 1984.

YOCUM, H.G. Factors affecting the germination of palm seeds. The American Horticultural Magazine, Washington, v.43, n.2, p.104-106, 1964. 